\title{
LOW-LEVEL LIQUID SCINTILLATION COUNTER ARRAY WITH COMPUTERIZED DATA ACQUISITION AND AGE CALCULATION CAPABILITIES FOR ${ }^{14} \mathrm{C}$ DATING
}

\author{
J. E. NOAKES, J. D. SPAULDING \\ Center for Applied Isotope Studies, University of Georgia, Athens, Georgia 30602-4702 USA \\ and
}

R. J. VALENTA

Packard Instrument Company, Downers Grove, Illinois 60515 USA

\begin{abstract}
We describe a two-phase study directed toward background reduction of a manual liquid scintillation counter and the interfacing of electronics for counting to a computer data acquisition system. Counter background reduction is achieved with afterpulse electronics, a high-performance cocktail, an auxiliary detector/guard and a special sample vial holder. The data acquisition system is comprised of an electronic signal processor and sorter for operating up to eight counters simultaneously and interfacing to a computer with software for data storage, acquisitions and age dating calculations. We discuss low-background counter modifications, electronic signal processing and computer software for ${ }^{14} \mathrm{C}$ age dating.
\end{abstract}

\section{INTRODUCTION}

In order to promote and maintain efficient, cost-effective operations in an analytical laboratory, periodic evaluation of existing procedures, instrumentation and data reporting methods is necessary. The continual evolution of liquid scintillation counting (LSC) technology demands that a ${ }^{14} \mathrm{C}$ laboratory realistically assess its required instrumentation performance, weighing the associated costs of upgrade $v s$. replacement and the practical benefits that can derive from the dollar cost invested. Following a recent evaluation of its ${ }^{14} \mathrm{C}$ dating laboratory, the Center for Applied Isotope Studies (CAIS) at the University of Georgia has decided to replace older LSC units; in doing so, it established a procedure that may assist other laboratories making similar decisions.

The CAIS presently uses four highly modified Picker Nuclear Liquimat 220 LS counters, ca. 26 yr old, for routine counting of low-level ${ }^{14} \mathrm{C}$ samples for age dating. For high-precision work, Packard Tri-Carb ${ }^{\circledR} 2260 \mathrm{XL}$, Packard Tri-Carb ${ }^{\circledR} 2550 \mathrm{TR} / \mathrm{AB}$, or Wallac Quantulus ${ }^{\mathrm{TM}} 1220$ LS counters are used. The Picker 220 counters have been repeatedly updated with electronic circuitry so that the redesigned 20 ns coincident circuit boards are the only original electronic components remaining. While the sample delivery system and external $5.1-\mathrm{cm} \mathrm{Pb}$ shielding are essentially original, the photomultiplier tubes (PMTs), preamplifier, amplifier, high-voltage multichannel analyzer (MCA) and digital processing capability have also been added or completely modified. In deciding to replace the four Picker 220 counters, the CAIS determined that a further upgrade in circuitry for the counters was unlikely to deliver the counting capabilities and low backgrounds that would be achievable with an equivalent investment in new, commercially available LS counters.

We used a two-phase method to determine the most cost-effective configuration of LS hardware and software to meet the needs of the CAIS laboratory. In the first phase, we assessed commercially available LS counters and selected a counter that could be readily modified for low-background, high-efficiency ${ }^{14} \mathrm{C}$ counting. In the second phase, we designed an appropriate data acquisition and reporting system to work with the instrumentation selected.

\section{LIQUID SCINTILLATION COUNTER SELECTION}

In choosing the LS counter, we considered the unit cost and the specified performance parameters for counter stability, background and counting efficiencies. For ${ }^{14} \mathrm{C}$ dating, an $\mathrm{LS}$ counter with a 
manual sample changer was more desirable than a counter with an automated multisample changer, owing to the limited number of samples available for counting at any given time. Also, manual units cost substantially less than automated ones. Selection is limited, as the Packard Instrument Company is, to our knowledge, the only firm presently marketing a manual LS counter. The Packard TriCarb ${ }^{\circledR}$ Model 1000 Liquid Scintillation Analyzer nevertheless meets the established criteria for cost and counting performance, and is designed so that modifications for reducing system background can be made with a minimal revision of physical and electronic configurations.

The Tri-Carb ${ }^{\circledR} 1000$ is a microprocessor-based LS counter with a full range of standard features and options (Packard Instrument Company 1986). The unit is versatile, accepting 7- or 20-ml samples in glass or plastic sample vials. With physical dimensions of $34.3 \mathrm{~cm}$ height $\times 80 \mathrm{~cm}$ width $\times 55.9 \mathrm{~cm}$ depth, the unit is relatively small and ideally suited for laboratories where space is a consideration. Total weight of the Tri-Carb 1000 counter is $140 \mathrm{~kg}$.

Two standard features of the Tri-Carb ${ }^{\circledR} 1000$ are of particular interest for use in ${ }^{14} \mathrm{C}$ dating: the Spectralyzer $^{\mathrm{TM}}$ spectrum analyzer for windowless counting, and three-dimensional spectrum analysis, which supplements coincidence counting and improves the discrimination of background radiation. During sample measurement, the spectrum analyzer stores and analyzes detected events, accumulating the entire spectrum of the radionuclide being measured. A pulse-height energy distribution spectrum is collected at a fixed gain over the entire energy range $0 \mathrm{keV}$ to $2000 \mathrm{keV}$, and the user can choose any region in this range for data analysis. The energy spectrum region is determined during sample measurement without the loss of either time or counts. Spectrum data are stored in 4096 linear channels for visual display, region optimization, pattern recognition, vector analysis and spectrum unfolding.

Three-dimensional spectrum analysis, or time-resolved counting, is a standard feature of the Tri$\mathrm{Carb}^{\circledR} 1000$ that is used to distinguish the background pulses of the sample vial and PMT envelope from true sample events (Roessler, Valenta and van Cauter, 1991; Valenta and Noakes 1988; Valenta 1987). Three-dimensional spectrum analysis, although functioning at only a minimal level in the Tri-Carb ${ }^{\circledR} 1000$, does discriminate, to a small degree, against the slow-decaying pulse components typical of scintillating glass, with a moderate reduction of background. Slow-decaying pulse components, or afterpulses, are counted for $c a .5 \mu$ following each coincident event and a pulse index is determined. The pulse index is used to discriminate background and to validate scintillation counts. Three-dimensional analysis usually results in a reduction in counting efficiency because sample events may occasionally be misclassified as background events. However, the significant reduction in background is usually more than sufficient to compensate for the loss in counting efficiency and results in an increased figure of merit $(\mathrm{FM})\left(\mathrm{E}^{2} / \mathrm{B}\right)$.

Other standard features of the Tri-Carb ${ }^{\circledast} 1000$ include a full-function keypad for programming, auto-optimization of counting performance, built-in diagnostics for verification of system functions, and self-normalization and calibration. In the event of a power failure during operation, the unit will continue sample processing, with system memory protected by battery for at least $72 \mathrm{~h}$. Specifications for expected counting performance are presented in Table 1.

TABLE 1. Packard Tri-Carb ${ }^{\mathrm{TM}} 1000$ LS Performance Characteristics

\begin{tabular}{lcc}
\hline & Large vial $(20 \mathrm{ml})$ & Small vial $(7 \mathrm{ml})$ \\
\hline${ }^{3} \mathrm{H}$ efficiency & $60 \%$ & $58 \%$ \\
${ }^{14} \mathrm{C}$ efficiency & $95 \%$ & $94 \%$ \\
\hline
\end{tabular}


The Tri-Carb 1000 LS counter also has several optional features, three of which were selected for application in the CAIS laboratory: an electrostatic controller for electrical neutralization of sample vials, a user-programmable RS-232C interface and a $20 \mu \mathrm{Ci}{ }^{133} \mathrm{Ba}$ external standard for quench correction. Once the Tri-Carb ${ }^{\circledR} 1000$ hardware was in place in the CAIS laboratory, several steps were taken to optimize the low-level operational parameters of the system to achieve the highest FM for ${ }^{14} \mathrm{C}$ counting.

\section{OPTIMIZATION OF THE PACKARD TRI-CARB ${ }^{\circledR} 1000$ LS COUNTER}

The first step for system optimization was the preparation of two benzene test cocktails. One cocktail, designated $\mathrm{A}$, was a standard formula used for routine CAIS ${ }^{14} \mathrm{C}$ measurement, and consisted of a primary PPO fluor (47.8 $\mathrm{mg} \mathrm{g}^{-1}$ benzene) and a secondary dimethyl POPOP fluor $\left(16 \mathrm{mg} \mathrm{g}^{-1}\right.$ benzene). A second cocktail, designated B, was a formula reported by Cook and Anderson (1993), and consisted of a primary butyl PBD (2.8 $\mathrm{mg} \mathrm{g}^{-1}$ benzene) and a secondary fluor bis-MSB ( $3 \mathrm{mg} \mathrm{g}^{-1}$ benzene). The second cocktail was prepared as an alternate especially suited to counting using a Packard LS counter equipped with afterpulse electronics.

The 3-ml benzene test samples were contained in 7 - $\mathrm{ml} \mathrm{low}-{ }^{40} \mathrm{~K}$ glass sample vials with Teflon ${ }^{\circledR}$ cap liners. $\mathrm{A}^{14} \mathrm{C}$ activity level of $2500 \mathrm{dpm}$ was used for each of the ${ }^{14} \mathrm{C}$ standards, which were counted for $60 \mathrm{~min}$ throughout the controlled test. Background samples of the same 3-ml benzene volume were prepared and counted for $960 \mathrm{~min}$ throughout the tests. To determine the optimum window for achieving the highest ${ }^{14} \mathrm{C}$ counting efficiency and the lowest background count rate, data stored on the counter's 4096 multichannel analyzer during the sample count mode was downloaded to a 486 laptop PC to record the full energy spectra. Post-spectra processing enabled the optimum energy window for the highest $E^{2} / B$ values to be determined (Table 2).

TABLE 2. ${ }^{14} \mathrm{C}$ Low-Level Counting Performance

\begin{tabular}{|c|c|c|c|c|c|}
\hline Unit/Configuration & Sample & $\begin{array}{c}\text { Window } \\
(\mathrm{keV})\end{array}$ & $\begin{array}{l}\text { Background } \\
(\mathrm{cpm})\end{array}$ & $\begin{array}{c}\text { Efficiency } \\
(\%)\end{array}$ & $\begin{array}{c}\mathrm{FM} \\
\left(\mathrm{E}^{2} / \mathrm{B}\right)\end{array}$ \\
\hline Packard Tri-Carb ${ }^{\circledR} 1000$ & $\begin{array}{l}\mathrm{A} \\
\mathrm{B}\end{array}$ & $\begin{array}{l}19-92 \\
21-92\end{array}$ & $\begin{array}{l}3.64 \\
2.91\end{array}$ & $\begin{array}{l}60.5 \\
69.0\end{array}$ & $\begin{array}{l}1110 \\
1640\end{array}$ \\
\hline Packard Tri-Carb ${ }^{\circledR} 1050$ & $\begin{array}{l}\text { A } \\
\text { B }\end{array}$ & $\begin{array}{l}19-83 \\
18-78\end{array}$ & $\begin{array}{l}1.06 \\
0.96\end{array}$ & $\begin{array}{l}54.7 \\
68.3\end{array}$ & $\begin{array}{l}2820 \\
4860\end{array}$ \\
\hline $\begin{array}{l}\text { Packard Tri-Carb }{ }^{\circledR} 1050 \text { with } \\
\text { plastic vial holder }\end{array}$ & $\begin{array}{l}\mathrm{A} \\
\mathrm{B}\end{array}$ & $\begin{array}{l}12-71 \\
12-80\end{array}$ & $\begin{array}{l}0.70 \\
0.88\end{array}$ & $\begin{array}{l}61.4 \\
79.0\end{array}$ & $\begin{array}{l}5390 \\
7090\end{array}$ \\
\hline $\begin{array}{l}\text { Packard Tri-Carb } \\
\text { plastic detector }\end{array}$ & $\begin{array}{l}\mathrm{A} \\
\mathrm{B}\end{array}$ & $\begin{array}{r}11-87 \\
7-86\end{array}$ & $\begin{array}{l}0.43 \\
0.60\end{array}$ & $\begin{array}{l}58.0 \\
81.8\end{array}$ & $\begin{array}{r}7820 \\
11,150\end{array}$ \\
\hline $\begin{array}{l}\text { Packard Tri-Carb }{ }^{\circledR} 1050 \text { with } \\
\text { plastic vial holder } \\
\text { and plastic detector }\end{array}$ & $\begin{array}{l}\text { A } \\
\text { B }\end{array}$ & $\begin{array}{l}10-82 \\
11-81\end{array}$ & $\begin{array}{l}0.41 \\
0.33\end{array}$ & $\begin{array}{l}57.9 \\
73.1\end{array}$ & $\begin{array}{r}8180 \\
16,190\end{array}$ \\
\hline $\begin{array}{l}\text { Packard Tri-Carb }{ }^{\circledR} 1050 \text { with } \\
\text { BGO detector }\end{array}$ & B & $14-86$ & 0.35 & 68.5 & 13,410 \\
\hline $\begin{array}{l}\text { Packard Tri-Carb }{ }^{\circledR} 1050 \text { with } \\
\text { BGO vial holder } \\
\text { and BGO detector }\end{array}$ & B & $15-88$ & 0.22 & 65.2 & 19,320 \\
\hline
\end{tabular}




\section{OPTIMIZATION OF THE PACKARD TRI-CARB ${ }^{\circledR} 1050$ LS COUNTER}

Upgrading the Tri-Carb 1000 LS counter to a Packard Tri-Carb 1050 low-level counter involved no real physical alterations and only minor electronic considerations. Basic to the electronic changes was the selection of a matched set of low dark noise PMTs $(<20,000 \mathrm{cpm})$ and the introduction of a greater degree of pulse spectral discrimination by the insertion of a read-only memory (ROM). The higher level of spectral analysis imposed on scintillation events reduced ${ }^{14} \mathrm{C}$ counting efficiency by ca. $6 \%$ for cocktail $\mathrm{A}$ and $1 \%$ for cocktail $\mathrm{B}$. In some cases, such reduction may result in rejection of valid counts. However, background is substantially reduced, to a level where the $E^{2} / B$ of the counter is significantly increased.

Low-level count mode performance tests on the Tri-Carb ${ }^{\circledR} 1050$ were carried out using the same A and $\mathrm{B}{ }^{14} \mathrm{C}$ standards and background samples as those used in tests of the Tri-Carb ${ }^{\circledR} 1000$ counter. The ${ }^{14} \mathrm{C}$ standards and background samples were counted for the same 60 - and 960 -min count times as in earlier tests so as to maintain equivalent performance criteria. Data gathered from the tests are presented in Table 2.

\section{OPTIMIZATION OF THE PACKARD TRI-CARB ${ }^{\star} 1050$ LS COUNTER WITH AUXILIARY SCINTILLATORS}

The use of auxiliary scintillators for enhanced afterpulse low-level LS counting was first reported by Noakes and Valenta (1989). Both organic and inorganic scintillators, possessing good optical properties for 4000-5000 $\AA$ photons and a slow decay fluorescent component, have been shown to be suitable for this application. These materials, fashioned as vial holders or guard detectors and positioned between the phototubes, are effective in achieving low-background LSC.

We performed initial optimization tests for the Tri-Carb ${ }^{\circledR} 1050$ with auxiliary scintillators using a scintillation plastic having a slow decay fluorescent component of $250 \mathrm{~ns}$, which was fabricated as a vial holder and guard. Both plastic components are commercially available from Packard Instrument Company as Pico-XL ${ }^{\mathrm{TM}}$ low-level vial holder and guard. Table 2 shows optimum counting results for the 3-ml benzene A and B standards and background. We carried out a second series of optimization tests with the Tri-Carb ${ }^{\circledR} 1050$ using an inorganic crystalline bismuth germanate $\mathrm{Bi}_{4} \mathrm{Ge}_{3} \mathrm{O}_{12}$ (BGO) vial holder and guard. BGO possesses excellent optical properties for the 4000-5000 $\AA$ photons and a slow-decay fluorescent component of $300 \mathrm{~ns}$. Table 2 presents results of these optimization tests using the $\mathrm{B}$ standard and vial/guard combinations, which show the highest achievable $\mathrm{E}^{2} / \mathrm{B}$ at 19,320. Figure 1 shows a long-term Tri-Carb ${ }^{\otimes} 1050$ background count stability evaluation using the 3-ml benzene B cocktail sample and a BGO vial holder and guard. The result of 29 repeated 100-min counts was a chi-square value of 34.2 (for $n=29$, the acceptable range is 19.8-39.1) and a reliability factor (RF) of 1.056 (for $n=29$ the acceptable range is $0.81-1.15$ ), where $R F$ is defined as the sample standard deviation divided by the square root of the mean.

\section{DESIGN OF THE DATA ACQUISITION SYSTEM}

The second phase of the CAIS laboratory upgrade involved the design of an appropriate data acquisition system to operate with the network of Tri-Carb 1050 LS countcrs. The overall design is based on the data acquisition system presently used by CAIS, which has performed efficiently and consistently for several years. The system consists of an electronic interface in each LS counter, a sorter that can accept data from up to eight counters simultaneously and a computer with software for data acquisition, storage and age dating calculations (Fig. 2). An uninterruptible power supply consisting of a battery charger, batteries and an inverter isolates the system electronics from power surges and from power outages of up to $12 \mathrm{~h}$. 


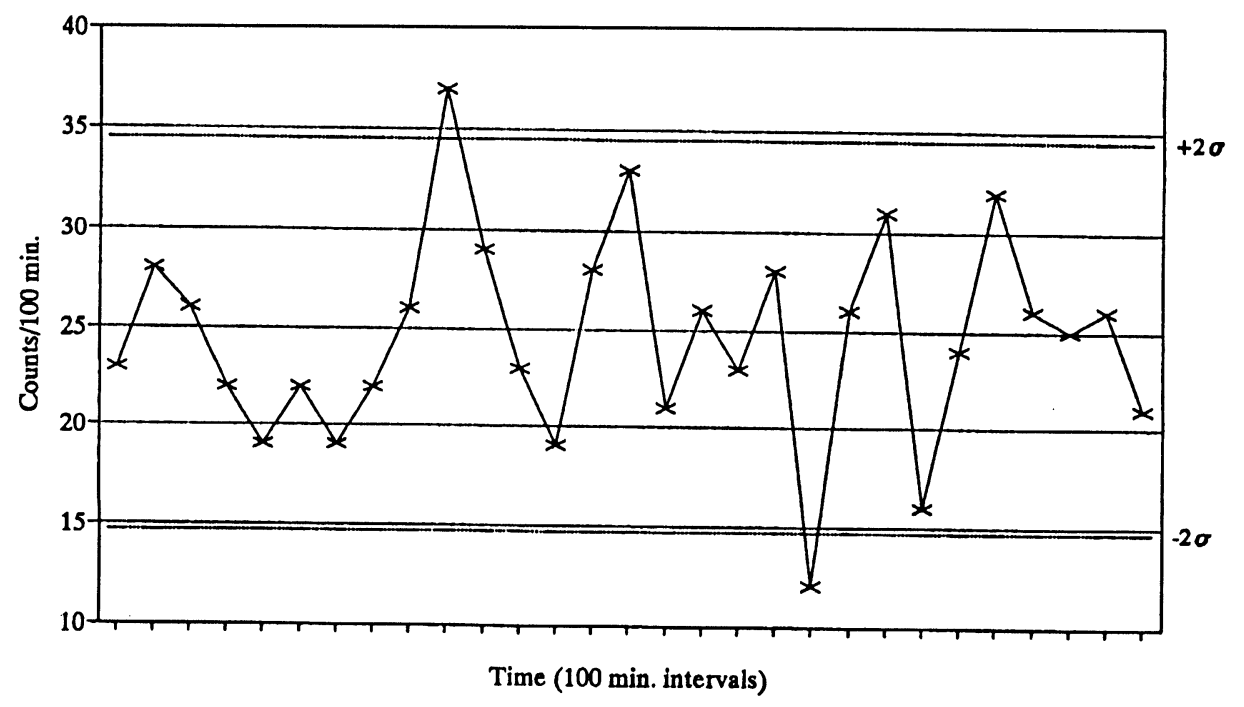

Fig. 1. Packard Tri-Carb 1050 background count stability evaluation

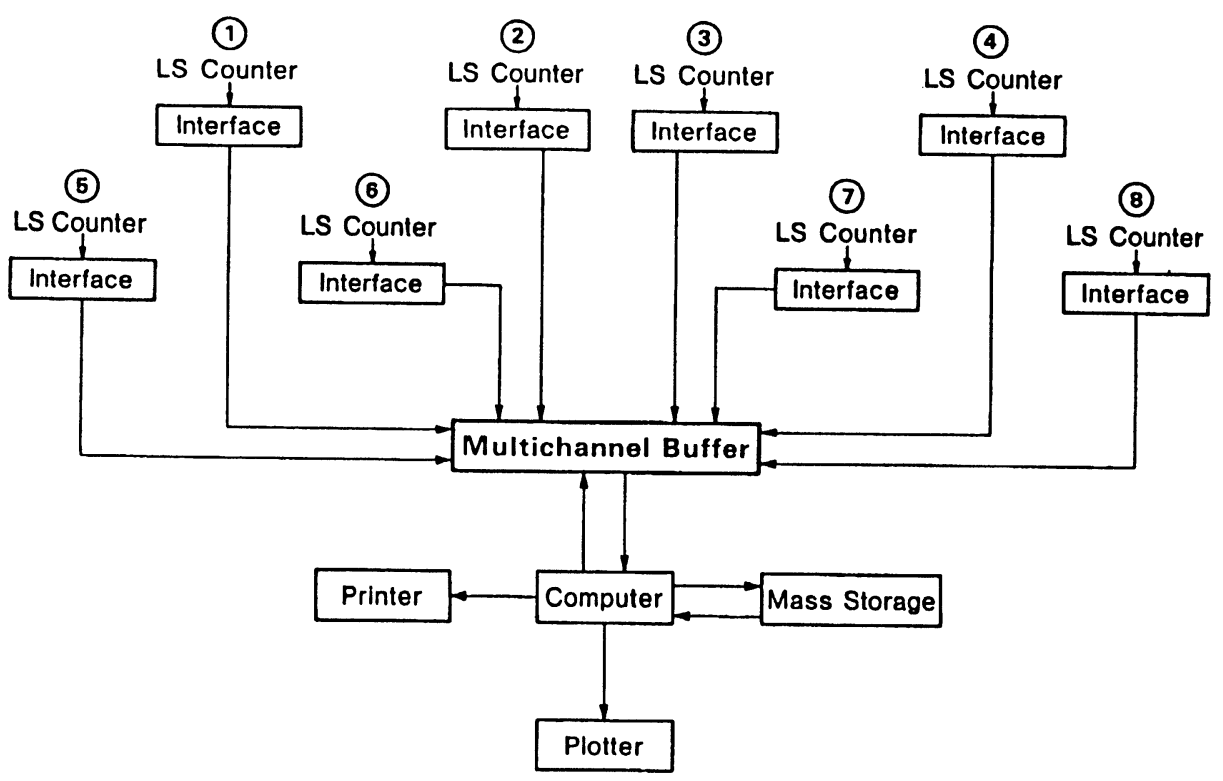

Fig. 2. CAIS LS counter data-acquisition system

Our modifications of the Picker 220 counters have included changes in the data-acquisition electronics. Originally, each counter was equipped to output raw data in a printed format, which was then collected and manually input to in-house programs for data reduction and age calculation. Over a decade ago, much of this electronic system was bypassed with custom-built electronic interface cards that were added to each counter. The interface cards served to invert and shape the arriving pulses, feed them into a multiplexer MCA and network the separate counters. The MCA was interfaced to a HP 150 computer that had been selected for its superior high-resolution graphics. 
For age dating, samples are counted for $2700 \mathrm{~min}$ and complete spectra are saved to floppy disk. Region of interest (ROI) integrals are recorded every $100 \mathrm{~min}$. At the completion of counting, data is tested for statistical validity, $\delta^{13} \mathrm{C}$ correction factors are applied, and the age is calculated based on resulting counts per minute and the weight of the sample. Figure 3 shows an example of the system output. All sample spectra and raw data are archived on disk at the CAIS laboratory. The new Tri-Carb ${ }^{\otimes} 1050$ LS counters, with higher counting efficiencies and lower backgrounds, will be networked in a similar fashion. The new data acquisition system will be updated with the use of new components, including a hard disk for the operation of software and for temporary storage.

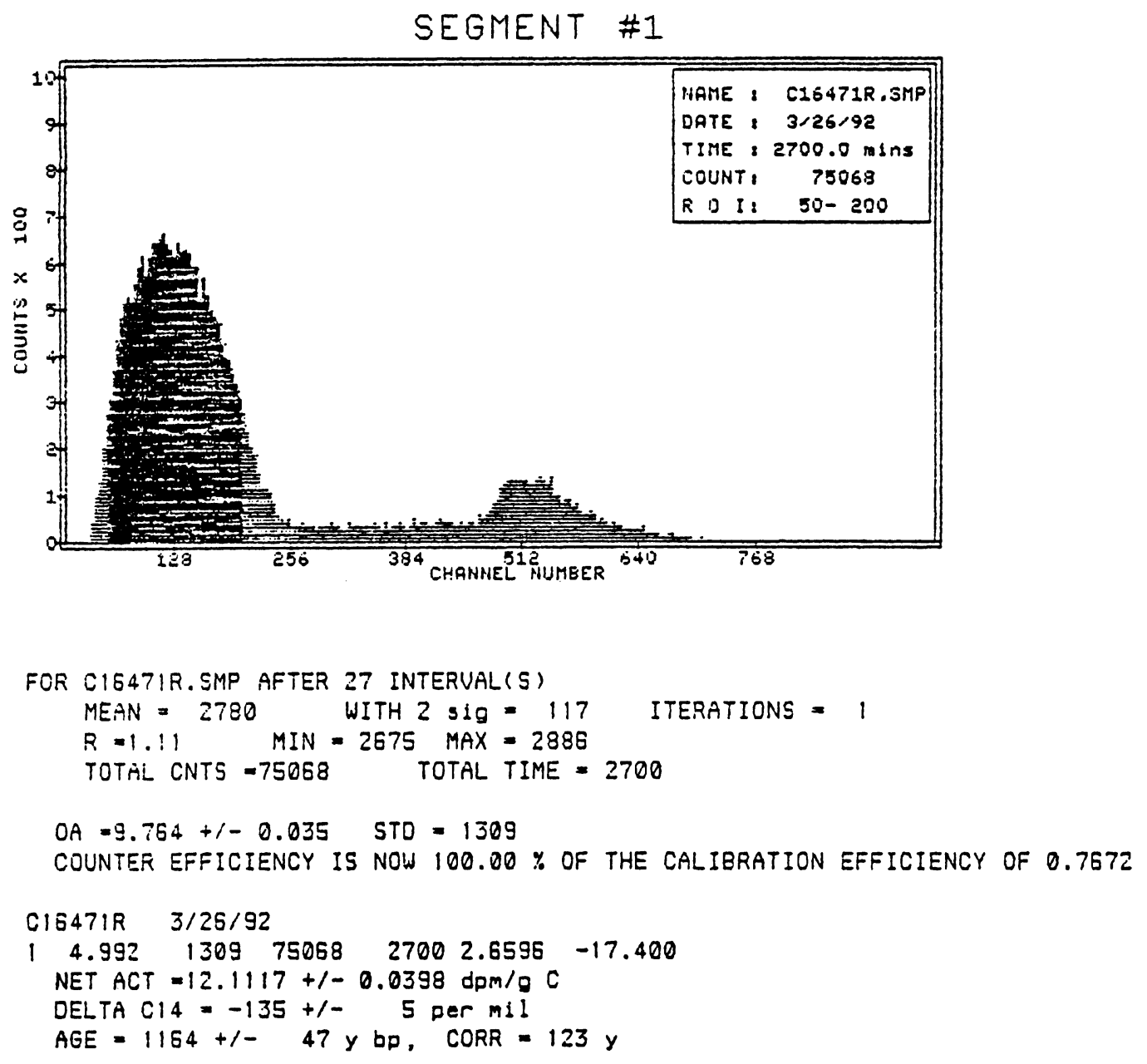

Fig. 3. Data-acquisition system output for CAIS LS network

\section{CONCLUSION}

The CAIS has demonstrated a stepwise procedure that can be applied by laboratories seeking to upgrade low-level ${ }^{14} \mathrm{C}$ counting capabilities in a cost-effective manner. A relatively low-cost, commercially available manual LS counter, through the use of various upgrades and auxiliary scintillators, can be used to reduce the background substantially and improve counting efficiency. Future 
studies using quartz or plastic sample holders rather than $7-\mathrm{ml} l o w-{ }^{40} \mathrm{~K}$ glass vials, a lowered temperature for the PMTs and delay-before-burst electronics should increase the $E^{2} / B$ of 19,320 achieved with this counter to $>20,000$. Optimum counting windows and resulting FMs have been defined for each upgrade alternative presented. The system can be enhanced with an appropriate data acquisition system that is capable of collecting, storing, reducing and presenting the data from a network of LS counters.

\section{REFERENCES}

Cook, G. T. and Anderson, R. 1993 Assessment of new features on a commercial liquid scintillation spectrometer for radiocarbon dating. In Noakes, J. E. Schönhofer, F. and Polach, H. A., eds., Advances in Liquid Scintillation Spectrometry 1992. Tucson, Arizona. Radiocarbon: 17-21.

Noakes, J. E. and Valenta, R. J. 1989 Low background liquid scintillation counting using an active sample holder and pulse discrimination electronics. In Long, A. and Kra, R. S., eds., Proceedings of the 13th International ${ }^{14} \mathrm{C}$ Conference. Radiocarbon 31(3): 332 341.

Roessler, N., Valenta, R. J. and van Cauter, S. 1991 Time- resolved liquid scintillation counting. In Ross, H., Noakes, J. E. and Spaulding, J. D., eds., Liquid Scintillation Counting and Organic Scintillators. Chelsea, Michigan, Lewis Publishers, Inc.: 501-511.

Packard Instrument Company, Inc. 1986 Tri-Carb ${ }^{\circledR}$ Liquid Scintillation Analyzer Model 1000 Operation Manual. Downer's Grove, Illinois.

Valenta, R. J. 1987 U.S. Patent 4,651,006: Reduced background scintillation counting.

Valenta, R. J. and Noakes. J. E. 1988 U.S. Patent $4,833,326$ : Improved liquid scintillation system with active guard shield. 